\title{
The Significance of Business Localization Factors in the Czech Republic
}

Eliška Jirásková, Miroslav Žižka

\section{Abstract}

This article is concerned with the significance of individual localization factors during the decision-making of economic subjects regarding the location of their businesses. In the first phase of the research, the investigated localization factors were divided into four groups into regional, local, business, labor and infrastructure. The selected localization factors were investigated with the help of an empirical examination of thirteen selected economic branches in the secondary and tertiary sectors. In subsequent stages, a statistical analysis of the acquired data was performed; the selected economic sections were compared among themselves; and with the help of a diffusion analysis, the dependence of the evaluation on the size of the enterprise and on the economic activities of the selected respondents was investigated. The main goal of the research was to identify the current localization factors associated with supplier and customer markets and to determine their significance. In the context of the research, the hypothesis was verified that despite the existence of various approaches to determining localization factors, in part there are localization factors that act universally in all economic branches and further factors that specifically manifest themselves only in some branches. In the context of each factor, investigated was whether the evaluation of a factor depends on the economic branch and whether it is possible to consider an investigated factor as universal. It was also determined whether or not the evaluation of a factor is directly proportionate to the size of the business. From the research results, it follows that during localization, businesses place the greatest significance on the availability of information and communications technologies, geographic proximity to customers, availability of qualified human resources and on transportation costs. Localization decision-making is affected by many factors and depends on a large number of circumstances.

Keywords: localization, location factor, analysis of variance, dependence, economic activity

Jel classification: C12, R 10, R 53

\section{Introduction}

An evaluation of the importance of factors by which economic subjects decide during the selection of a location for their activities ranks among the significant aspects of 
regional policies when shaping the business environment. This involves the current topic, which overall has not been devoted sufficient attention in Czech professional literature. For this reason, in the context of the research project "Analysis of selected localization factors and their comparison according to individual economic activities," 26 localization factors were investigated in 13 sections of the national economy according to the CZ-NACE classification.

Characterized in the first section of the article are localization factors as noted in the professional literature and the methodological starting points of the research. In this section, the research results are linked to the investigated localization factors as divided into four thematic groups for greater clarity. In the context of the analysis, their dependence on the size of the enterprise and on the type of economic activities was evaluated. Particular attention was devoted especially to regional and local factors in regard to their growing significance in recent times and at the same time due to the fact that less attention has been devoted to them in other research.

The main goal of the research is to verify the basic hypothesis that despite the existence of various approaches to determining localization factors, in part there are localization factors that act universally in all economic branches and further factors that specifically manifest themselves only in some branches. Associated with this hypothesis are the two parts of the hypothesis:

- The evaluation of an investigated factor depends on the size of the enterprise.

- The evaluation of the localization factor of geographic proximity to the competition declines with the size of the enterprise.

- The significance of the localization factor of geographic proximity to suppliers will be directly proportionate to the size of the company.

- In the case of the localization factor of the possibility of cooperation with the competition, its significance will decline with the growing size of the company.

\section{Localization factors}

The basic theme of localization theory is not merely to define localization factors, but also under the assumption of the rational behavior of economic subjects, to determine their optimal placement. In essence, this involves determining what location is appropriate for an economic subject to locate in order for its profit to be as high as possible in connection with spatial orientation. By means of the quality of localization factors, it is possible to characterize the attractiveness of certain locations and it is possible to see determinants such as the attractiveness of a given region as localization factors. Localization of a company is affected by a number of factors that continuously change, new factors appearing and on the other hand others disappearing. Correct localization may affect the profits and success of the given economic subject. Despite this fact, there are a large number of companies that have not yet conducted variant consideration of the optimal spatial placement and would rather select just a satisfactory variant. The reason for this ineffective behavior is the lack of access to information about individual regions and localities and the high costs associated with the collection and processing of this information. The team of Z. Matoušková (2000, s. 49) argues that one of the reasons for selecting so-called satisfactory variants is the fact that traditional localization factors, among which we rank for example transportation and labor costs, gradually lose significance and their impact on the decision-making regarding placement 
gradually weakens. This development of localization factors is caused primarily by technical advances in transportation, which significantly shorten distances. The decline in transportation costs and the removal of international trade barriers give investors greater room when selecting a suitable localization strategy and for direct foreign investment, which may be considered a key indicator in the development of a region (Hlaváček, 2009, s. 7) and plays a decisive and supportive role primarily in the creation and expansion of competitiveness in less developed countries. The reduction in transportation costs, the globalizing of the business environment and changes in the economic structure initially from primary to secondary and later to the tertiary sector, among other things, depends on the change in the importance of individual localization factors. For example, land, which played a significant role in the first localization theories of agricultural production, during early industrialization, was interchangeable with the proximity to raw materials and transportation advantages.

Currently, there are several viewpoints on the significance of localization factors, for details see Ježek (1998, s. 66). As is noted by J. Blažek and Uhlír (2002, s. 63), "currently considered as the main localization factors affecting the localization decision-making of multi-national companies at the national level in particular are macroeconomic and political stability, as well as price levels and market potential; at the regional level then an adequate labor force with corresponding qualifications, sufficient and advantageous prices for land, infrastructure quality, the proximity to scientific-research facilities, the quality of the environment in the broadest sense of the word, transportation connections, industrial traditions, etc."

Just as there is not one generally valid localization theory, it is impossible to unify even a survey of different individual localization factors into individual groups. In the context of this article, a selected typology of localization factors is presented and detailed attention devoted to factors that were analyzed in the context of the aforementioned research. M. Viturka $(1998$, s. 8) in his study divided localization factors into six groups: business, labor, costs, infrastructure, region and environment. Furthermore, recently an often used classification is the separation of localization factors into soft and hard factors, which may be considered as mutually complementary. This complementary nature originates from mutually close functional dependence between soft and hard localization factors. As an example of the division, it is possible to present the typology of the authors Dziembow-Kowalski and Funck, who divide localization factors by their impact. Considered to be hard are those that directly affect the regional disposition for a certain activity and have an immediate impact on net profit. Considered as soft are factors whose impact is not directly measurable in economic outputs, i.e. they do not appear in accounting ledgers. (Rumpel, et al, 2008, s. 14) Between these two groups, it is difficult to distinguish and in theory no consensus exists in their articulation, as it is impossible to precisely establish their mutual boundaries. Some authors therefore link the concept of "soft" with the less significant from the standpoint of the impact on regional development. Contrary to this B. Grabow and B. Hollbach-Grömig counter with the fact that soft localization factors could be significant without having to become hard factors. The above German scientists are the authors of the most implemented typology of localization factors, which includes:

- Hard and soft factors, the quality and level of which are primarily measurable and among which belong, for example, the availability of qualified human resources, the availability of space, transportation infrastructure, prices for spaces, buildings, etc. 
- Soft localization factors of business, which have an immediate impact on business activity, but are not primarily measurable, or depend on a subjective evaluation by the entrepreneur.

- Soft individual localization factors, which are matters of personal preference by management staff and employees and do not have an immediate impact on the activities of enterprises, but rather on affect motivation and effectiveness. (Rumpel, et al, 2008, s. 15)

Hard localization factors concern the following areas in particular:

- The labor market - level of pay, wages, options for employee for education, specialization in the labor market;

- The business environment and infrastructure - availability of space (industrial zones), non-residential and office space, the state of the transportation infrastructures (highways, airports, parking lots, public transportation systems, etc.);

- Prices, costs, revenues - prices for land and buildings, communal taxes and fees, subsidies and grants provided by cities, costs for energy, water, etc.;

- Markets, business relations, networks - proximity to other plants of the same enterprise, proximity to suppliers and sales markets, contacts with enterprises of the same or different sectors and cooperation with institutions of the public sector;

- Quality of the environment - purity of air and water, ecological requirements, conditions and standards. (Grabow and Hollbach-Grömig, 1995, s. 39)

As noted also by Slach, Rumpel and Koutský, currently the significance of hard localization factors is gradually declining as they become ubiquitous, i.e. generally available and accessible, by which they lose their privileged significance for localization. (Slach, et al, 2008, s. 13) Recently, greater significance has been attributed to soft localization factors. In future, it is possible to anticipate that regions that complement their development strategy for hard localization factors with a suitable diversified development strategy for soft factors will become more competitive. A huge disadvantage of soft factors is their difficult if not impossible measurability and thus the need for subjective evaluation. Localization may impact also the limited resources of a certain territory. Among other factors, which could have an impact on decision-making regarding the placement of companies or capital, from an international standpoint, include:

- The situation in the given country, whether or not foreign companies are desirable in the country and whether or not the inhabitants are prepared to buy from these companies or whether or not this does not risk significant deterioration of the situation in the country.

- The political-economic environment, when a company from abroad may come into contact with a centrally planned economy, where the government decides about everything, with a market economy which depends on the individual decision-making of economic subjects and the government intercedes only indirectly by creating conditions, or with a mixed economy which is characterized by both traits, i.e. on one hand there is a direct impact of centers that the enterprises have themselves and on the other hand the indirect impact of centers that only issue laws, administer public investment and provide public goods and services. (Ponikelský, 2008) 
- Political stability, which may be evaluated together with the macroeconomic situation as the most important localization factors. (Yemen Times, 2007)

- Laws, customs, limits to taxes in the country and thereby possible barriers to entry.

- Taxes, which are one of the main localization factors primarily in certain areas of business. As an example, it is possible to mention pharmaceutical companies that according to research locate primarily in locations with a low level of taxation for legal entities, for example in Ireland (Simango, 1993, s. 7), where in 2011 the level of taxation was only $12.5 \%$.

- Exchange rate system;

- Fiscal and monetary policy, where it is possible to mention primarily the amount of taxes and the possibility for preferential tax rates for newly arriving companies. From the research presented by $\mathrm{M}$. Wasylenko, however, it appears that fiscal variability does not have too great a significance for decision-making by managers regarding placement. (Wasylenko, 1991,

s. $13-30)$

- Distance of others from the countries to which we would like to import our products;

- Extent of taxation of the country;

- Foreign price levels;

- English, which is the language of many large companies;

- Comparative advantages derived from other territories;

- Openness of the economy toward other states;

- Facilities of the telecommunications infrastructure;

- Factors of movement, which originate from the greater or lesser mobility of individual activities. Among factors of movement we can include primarily migration of the labor force, transfer of capital and sensitive international relations, which share in the creation of large corporations. (Krugman and Obstfeld, 2009, s. 153)

- Labor costs, which could be regarded as quite differentiated in individual countries and for some economic branches could even be key. As a classical example of the shift into areas with a cheap labor force, it is possible to show India, where there is an English-speaking cheap labor force and large investment potential for large international corporations. (Traxler, 2009) In this direction, a shift in countries is occurring also to countries of central and eastern Europe, where a relatively qualified labor force is located for reasonable wages. (Sass, 2010, s. 45 - 63)

- Social sentiment and affiliated relations, which could be a decisive localization factor primarily in Asian countries. (He, C., et al 1997, s. 328 - 338)

- Raw material resources, which could affect us with its specificity or price availability.

- Age structure of the population, (Lechenko, R, 2003, s. 365 - 386) where again the example of India has an advantageous position, as in age, this is a very young area.

- Preferential loan conditions, which prove very good when attracting new capital;

- Investment grants, which are necessary when related to the creation of new jobs and to an expansion of job opportunities. Otherwise, new production activities may be 
attracted to the given area but will not have any positive impact on the development of the given region and in resolving the question of unemployment.

\section{Research methodology}

At the beginning of the research, an early goal was to classify the significance of the investigated factors and to verify the established hypothesis. In the first phase, it was necessary to select an appropriate technique for data collection, so that the technique for data collection was adequate for the requirements of the reliability and validity of empirical research. (Hnilicová a Bártlová, 2000, s. 25) Therefore, for implementing inquiries, it was determined to select the questionnaire as the most advantageous method, which was then sent in electronic form in the initial phase. In regard to the selected method of random selection of respondents, it was necessary to obtain questionnaires from the highest number of contacted companies, ideally from all of them. If the contacted respondents did not react to the electronic contact, they were subsequently contacted by telephone. Thanks to generally known knowledge about the low rate of return of electronic questionnaires, it was necessary to construct the questionnaire in such a way that they were the least time consuming and at the same time enabled inquirers to determine precisely and clearly the required information. Therefore, the questions were formulated on the basis of a so-called evaluation scale (with intervals of 1 absolutely unimportant; 2 somewhat unimportant; 3 not important or unimportant; 4 somewhat important; 5 absolutely important). The individual position of respondents could then be distinctly expressed on the scale using certain descriptive responses. In the next phase, it was necessary to define the selection samples, which we understand as subsets of the components of the basic set, which is selected deliberately or randomly and which is representative. (Kožíšek, J., et al, 2008, s. 12) The classifying mark of the described project was branch relevance according to the

CZ-NACE classification, which divides economic subjects into 21 sections. Not all sections, however, were in accordance with the purpose of the research, and therefore 13 sections were selected, from which 455 small and medium-sized companies were contacted. The selection of respondents originated from three sections of the secondary sector and from ten sections of the tertiary sector. Data collection was implemented in the period from April through September 2011. The rate of return of questionnaires was 95 percent. In the context of the research, only minor, small and medium-sized companies were contacted. From tab. 1, it is possible to clarify the percentage of representation in the received responses.

Tab. 1: Characteristics of contacted enterprises

\begin{tabular}{|l|c|c|}
\hline CATEGORY OF ENTERPRISES & NUMBER OF RESPONSES & $\begin{array}{c}\text { \% OF TOTAL NUMBER } \\
\text { OF RECEIVED RESPONSES }\end{array}$ \\
\hline MINOR & 224 & $52 \%$ \\
\hline SMALL & 145 & $33 \%$ \\
\hline MEDIUM & 66 & $15 \%$ \\
\hline
\end{tabular}

\section{Source: own}

The investigated localization factors were divided into four groups into regional, local, business, labor and infrastructure. Individual groups then include hard as well as soft localization factors, which are described in the text below. 


\section{Investigated regional and local localization factors}

In the context of the research, a total of 15 factors were included in these groups, which in some manner affect the given locality and region. At the same time, this category included the largest number of soft localization factors, whereas sufficient attention has not been devoted to these factors in professional literature and has not been mapped much in the Czech Republic. (Slach, O., et al, 2008, s. 15 - 24) Individual evaluating factors of respondents are noted in fig. 1 . From the figure, it follows that the most important for decision-making regarding localization are the factors availability of information and communications technology, as well as the economic state of the region and the prices for land and buildings.

Fig. 1: Evaluation of regional and local factors

\section{Regional and local factors}

The quality and attractiveness of the territory

The tradition and history of the locality

The facilities of the city

Availability and quality of research facilities

The economic state of the region

The availability of non-residential and office spaces

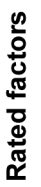

Prices for land and buildings

Cooperation with state authority

The quality of employment offices

Amount of taxes and fees

Ecological requirements, conditions and standards

The availability of information and communications technology

The presence of foreign companies

The image of the region

Possibilities for use of free time

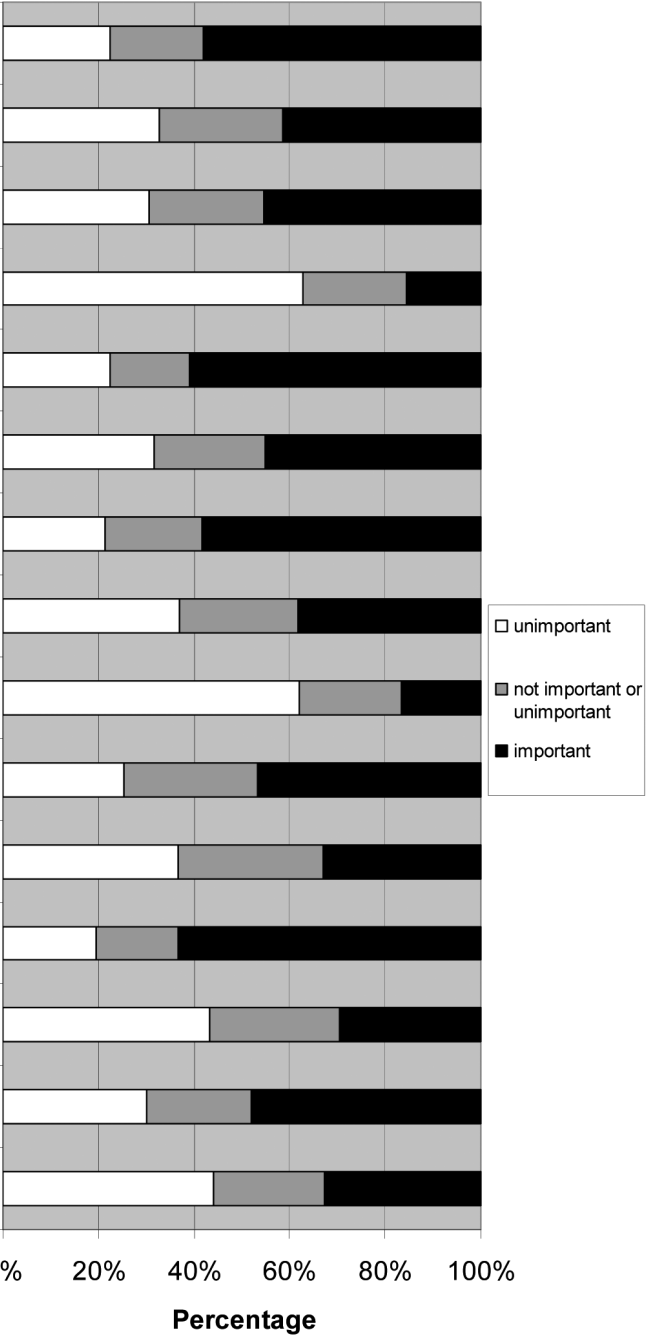


The quality and attractiveness of the territory was the first part of the investigated localization factors, while it is possible to state that "the quality of the environment is one of the decisive criteria for localization of residence for higher income groups." It is anticipated that companies in all investigated economic branches will make an effort toward localization in areas with highly attractive territories, and that this factor will play a pivotal role during localization. In the concept of our research, this factor is interpreted as the universal attractiveness of the given territory for newly arriving companies. From the research results, it follows that this factor can be marked as somewhat important for decision-making regarding localization. The quality of the attractiveness of a territory was evaluated by $59 \%$ of respondents as important, $19 \%$ as a neutral factor and for $22 \%$ of respondents this factor was considered as unimportant. The acquired values were further investigated from the standpoint of average and mode, whereas the average value attained the amount of 3.46 and as this factor was considered as the most important in the area of real estate, accommodation and dining. Evaluated as the least important factor was in the area of education (average value of 2.84), where at the same time, the most frequent response presented was that for the given area, the factor was "absolutely unimportant." For a better interpretation, the individual branch was evaluated also from the standpoint of the mode from which it is possible to clarify that this factor was predominantly higher than the average value of the given factor. From the standpoint of the secondary and tertiary sector, it is not possible from the research results to render a uniform conclusion, while in both sectors this evaluation was entirely consistent. Each factor was further evaluated from the standpoint of the dependence of the evaluation on the size of the enterprise and economic activities. For the quality and attractiveness of the territory, it is possible to state that it was not possible to reject the hypothesis at the $5 \%$ level of significance in regard to the dependence of the evaluation of the factor on the size of the enterprise. At the same time, at the $5 \%$ level of significance, the hypothesis was confirmed regarding the dependence of the evaluation of the factor on economic activity; the close dependency, however, was relatively weak (determination index 0.08). This factor may be considered as universal.

Furthermore, the tradition and history of the locality was investigated. This factor also may be ranked in the group of soft localization factors. For this factor, in the initial considerations, greater significance was not anticipated in the context of all investigated branches. It is possible to assume that a greater significance of this factor will be evaluated rather by companies established in this history and whose economic branch is associated with the history. On the other hand, it is impossible to assume greater significance in new and dynamic branches. Furthermore, the assumption was addressed in that the given factor would be less significant in the tertiary sector in comparison with the processing industry. From fig. 1 it is possible then to clarify that the tradition and history of a locality was evaluated by respondents very differently. Often, the values approximated an average value of

3 (total average value is 3.02). The given factor was evaluated as important by $41 \%$ of respondents, as unimportant by $33 \%$ of respondents and the remaining part consider it as neutral during decision-making. From the research, it also follows that this factor was evaluated best in the sections of accommodation and dining and administrative and support activities. The slightest significance of this factor was then recorded in the newest branches, particularly in the sections of professional, scientific and technical activities, information and communications activities, in financial and insurance and in the area of education. From the standpoint of the average and mode, however, it is impossible to come to a definitive conclusion that the given factor was evaluated in some 
branches significantly differently than in others. From the standpoint of comparing subjects in industry and services, the tradition and history of the locality was evaluated as somewhat more important for industrial enterprises. The assumption was therefore verified that this factor is assessed greater significance for economic activities related to history. The dependence of the evaluation of factor was demonstrated at the level of significance of $5 \%$ only from the standpoint of economic activities; while the overall closeness was very weak (determination index 0.06).

In the case of the third regional factor, the facilities of the city were investigated, i.e., what emphasis companies place during their decision-making regarding placement on the healthcare network in the given area, cultural opportunities, education facilities, etc. This factor also ranks in the group of soft localization factors and it is possible to assume that the quality of city facilities is beneficial primarily in the case of the needs of qualified human resources, which select where they will work and adequate city facilities for them is one of the decisive criteria. As is clear from fig. 1 , this factor thus is evaluated by nearly half of respondents (45 \%) as "somewhat important" or "absolutely important." Furthermore, a quarter of the respondents whose decision is unaffected by this factor either positively or negatively and the remaining part evaluated it as unimportant. This factor was then evaluated above average in the areas of administrative and support activities, information and communications activities and by activities relating to real estate. The facilities of the city were evaluated as the least important by respondents from professional, scientific and technical activities and in education. From the standpoint of comparing subjects of industry and services, a significant difference was not found and the dependence of the evaluation of the factor on the size of the enterprise or on the economic branch was not demonstrated at the level of significance of $5 \%$.

Availability and quality of research facilities also belong to the group of soft localization factors. The original assumption was that its importance would not be consistent for all investigated economic activities. They do not need some activities, which are already in essence research facilities. From fig. 1 it is apparent that the evaluated factor is evaluated predominated significantly as unimportant (62\%). It was marked as important by $16 \%$ of respondents and for the remaining $22 \%$ the quality of research facilities has a neutral impact. The total average value fluctuated around a value of 2, which is marked as "somewhat unimportant." The largest significance, with an average mark of 2.4, was recorded for this factor in the section "supply of water, services associated with waste waters, waste and sanitation." On the other hand, the factor was evaluated as the least important by respondents in the areas of transportation, activities related to real estate and in the areas of accommodation and dining. In all branches of the tertiary sector, the factor was most frequently marked as "absolutely unimportant." The factor plays a more significant role in industrial branches. The hypothesis regarding the dependence of the evaluation of the factor on economic activities was not demonstrated at the level of significance of $5 \%$. Therefore, it is possible to state that the availability and quality of research facilities does not rank among universal localization factors. But the hypothesis regarding the dependence of localization decision-making on the size of the enterprise was confirmed, although in this case it is merely weak (determination index 0.015). Therefore, it is possible to state that the availability and quality of research facilities plays a more significant role for larger companies engaging in industrial production.

The economic state of the region as a localization factor is closely related to regional policy and strategic planning. From fig. 1 it is apparent that this factor was evaluated by 
the contacted respondents as somewhat important. Specifically, 61\% of respondents evaluated it with a mark higher than three and only $22 \%$ marked it as unimportant. As the most important, this factor was evaluated in the section of activities in the area of real estate, as well as in construction and in the section of wholesale and retail. On the other hand, this factor was evaluated as less important in the section of education, where the average value is 2.9 and where it was most often noted that the factor did not have "absolutely any" impact. From a sector standpoint, no significant difference was found in the evaluation of the importance of this factor. The hypothesis regarding the dependence of the evaluation of the factor on the size of the enterprise did not demonstrate a level of significance of $5 \%$. But, it is possible to consider this factor as universal from the standpoint of investigated economic activities, whereas dependence of the evaluated factor on economic activity demonstrated a level of significance of $5 \%$. However, the determination index was 0.07 , i.e. the closeness of the dependence is weak.

The availability of non-residential and office spaces may already be included among the classic hard localization factors. Generally, it is possible to consider this as a somewhat important factor when deciding on localization, as in our research it was evaluated by nearly half of the polled companies (45\%) as important, by a third as unimportant and the remaining respondents with no impact on decision-making regarding localization (see fig. 1). In regard to the extent of the variability in responses at this factor, it is possible to assume a marked skewing of average values and a greater corresponding ability whether or not this therefore has a mode. From the research results, it follows that this factor was the most significant in the areas of wholesale and retail. Furthermore, this factor appears as significant in the areas of real estate and in construction. On the other hand, less importance was recorded for this factor in the area of transportation, for other professional, scientific and technical activities and in the section of education, where the average value fluctuated only around 2.5. From the standpoint of the evaluation in the context of a comparison of subjects of the secondary and tertiary sectors, this factor was evaluated consistently by $45 \%$ of respondents as important and by nearly a third as unimportant. For the remaining respondents, the availability of non-residential and office spaces played a neutral role. From the standpoint of the size of the company, the level of significance of $5 \%$ was not confirmed for the dependence of the evaluation of the factor on the size of the company. But, dependence of the evaluation of the factor on the type of economic activity was demonstrated. The closeness of dependence here was measured as the highest of all factors (0.1). The availability of non-residential and office spaces then may be noted as a universal factor.

The factor of prices for land and buildings in some parts (see, for example Viturka) is also included in cost factors. Due to the greater transparency of the questionnaire, the factor was ranked into regional and local factors. From the standpoint of hard and soft factors, we include it among classic hard factors and it is possible to anticipate that this factor will be very essential for companies in all branches. From fig. 1, it is possible to read that this factor was evaluated as "somewhat important" to "absolutely important" by $59 \%$ of respondents; only $21 \%$ considered it as unimportant and the remaining $20 \%$ evaluate it as neutral. On average, this factor was evaluated by a mark of 3.5, which ranks it among the most significant factors from the standpoint of deciding on a company's localization. Above average values were recorded at real estate offices and in construction, as well as for wholesale and retail, administrative and support activities. On the other hand, the factor was evaluated strongly below average in the areas of education 
and transportation, where it was most frequently noted that the given factor did not have either a positive or negative impact on decision-making regarding location of the company. Generally, it is possible then to consider this factor as significant for nearly a third of all investigated economic activities and a more essential difference was not recorded even from the standpoint of sectors. Dependence of the evaluation of the factor on the size of the enterprise was not demonstrated, but a weak dependence was demonstrated (determination index of 0.05 ) for evaluation in the economic branches. The factor prices of land and buildings may then be considered as universal.

Under the localization factor cooperation with state authority in essence it is possible to present cooperation with communal, municipal or regional authorities, with the courts, legal executors, with CZECH POINT, etc. This factor also belongs in the category of soft localization factors. Therefore, it was not anticipated that this factor would play a more significant role during the decision-making regarding placement of an economic subject. The majority of companies come into contact with the state authorities only a few times a year. This factor was therefore included in the questionnaire inquiry rather to ensure whether or not only some branches exist for which cooperation with state authorities plays a more significant role and for the attraction of which into the given areas should this cooperation be qualified. From the research results, it follows that from the standpoint of the impact on localization decision-making, this factor was assessed great significance by $38 \%$ of respondents and on the other hand for $37 \%$, the factor was evaluated as unimportant (see fig. 1). For the remaining quarter of respondents, the respondents were indifferent to the factor when deciding on placement. The research results also show a greater significance of cooperation with state authorities in the case of industrial enterprises. The most frequent response for subjects in the branches of construction, water supply and also for processing industry was the variant that for the area, this factor was "somewhat important." Overall, this factor was evaluated in the secondary sector as important by $45 \%$ and in the tertiary by $35 \%$ of respondents. From the standpoint of average values, the factor was the least significant for the area of finance and insurance, as well as for the areas of education, transportation and professional, technical and scientific activities. At the level of significance of $5 \%$, it was demonstrated that the evaluation of the factor depends in direct proportion to the size of the enterprise, although the subsequent closeness of dependence was only 0.023 . Dependence among the evaluation of the factor and the type of economic activity did not show a level of significance of $5 \%$ and therefore this factor cannot be considered as universal.

The localization factor related to the quality of employment offices ranks among the group of soft localization factors, the significance of which is currently on the rise, although for this factor, it is not anticipated that it would have a greater impact on the decision-making on localization. This factor may be considered by larger companies as insignificant, but they do not work with the employment office or they do not have sufficient information about its activities. For this localization factor, it is possible to anticipate that greater significance will be given to it by companies that rely on the availability of qualified human resources. From fig. 1, it is possible to read that the most asked respondents (62\%) evaluated it as "absolutely unimportant" or "somewhat unimportant” for deciding on placement. Little significance was apparent also from average values, when the highest average value was recorded in the areas of processing industry and in construction. In all branches, overall this factor was more frequently evaluated as "absolutely unimportant," which also corresponds to its little significance. If 
we would like to compare subjects in the secondary and tertiary sector, then the factor was evaluated as less important in the subject of services. From the standpoint of dependence of localization decision-making on the size of the enterprise, a weak dependence was demonstrated by a level of significance of $5 \%$ (determination index 0.028). From the research results, it is possible to come to the conclusion that the quality of the employment office plays a somewhat larger, but not essential, role in decision-making for large and industrial enterprises. Dependence of the evaluation of the factor and the type of economic activities did not show a level of significance of $5 \%$ and therefore this factor cannot be considered as universal.

Amount of taxes and fees was ranked in hard localization factors, although by reason of the essential universality in the context of a single state, we did not assume a large significance in the investigated branches. It is perhaps possible to assess greater importance for it only for property taxes or for local fees, which differ in individual cities and communities. From the research results, it then follows that this factor is important when deciding on placement for roughly half of the asked respondents. On the other hand, roughly a quarter consider it as unimportant and for the remaining respondents this factor has neither a negative nor positive impact on decision-making. The ambiguity of the evaluation of this factor on decision-making about placement of an economic subject, for example in the section of other activities, where it was most frequently cited, is that the factor is "absolutely unimportant" during decision-making and the average mark was then 3.11. The average values do not differ much from one another in individual sections, although it is possible to consider this factor as more important in the secondary sector, where $55 \%$ of respondents noted it with a mark of 4 or 5 . In the tertiary sector, the amount of taxes and fees is considered as an important factor by $11 \%$ fewer respondents. The dependence between the evaluated factor and the size of the enterprise did not demonstrate a level of significance of $5 \%$. The dependence between the evaluated factor and economic activities was demonstrated, although it was very weak (determination index 0.06). The amount of taxes and fees therefore may be considered as a universal localization factor, as it carries greater weight on the decision-making of industrial companies.

In the context of the factor ecological requirements, conditions and standards it was investigated to what degree ecological requirements affect the placement of individual economic subjects. It is possible to include it in the group of hard factors, although great significance is not anticipated for it. This assumption was confirmed by the research results, where only roughly $37 \%$ of asked respondents considered it as important during decision-making. This factor was evaluated as neutral by a third of those questioned and the remaining respondents noted that this factor did not have any impact during decision-making on localization (see fig. 1). It is also possible to state that the given factor has greater significance on the decision-making of companies from the industrial branch when this factor was evaluated by $52 \%$ of respondents as important. In the tertiary sector, the importance of the factor was confirmed by only $27 \%$ of respondents. From the standpoint of economic activities, the factor was evaluated as the least important in the sections of finance, insurance and education. Also at a level of significance of $5 \%$, it was found that the significance of the factor grew with the size of the enterprise, although the degree of dependence again is very weak (somewhat less than 0.02). In conclusion, it is possible to state that ecological conditions, requirements and standards affect rather larger industrial companies. From the standpoint of the 
investigated economic activities, it is also possible to consider this factor as universal, as dependence was demonstrated in evaluating the factor on the type of economic activity.

The availability of information and communications technology can be included in soft localization factors, particularly in regard to the fact that in the past, this factor was not considered as much in connection with localization decision-making primarily thanks to the relatively short-term existence of these technologies. As a result of the huge information and telecommunications boom, however, it is possible to anticipate a growing influence of this factor. A more emphatic impact then is anticipated in dynamic and rapidly developing branches, which cannot get by without information and communications technologies. From the research results and from fig. 1, it also follows that this factor was evaluated as important by $63 \%$ of respondents. Therefore it is possible to come to the conclusion that this factor plays a significant role for larger companies and the facilities for these technologies should be included in the regional competitive strategy. Furthermore, a distinct significance of this factor is apparent in all the investigated branches. In five of the investigated areas of services, it was even most frequently noted that communications and information technologies are "absolutely important" for localization of an enterprise. The large significance of this factor is apparent not just from mode, but also from the average values, which fluctuate around 4 . For information and communications activities and retail and wholesale, it is even evaluated above the value of 4, i.e., that on average, this factor was evaluated by respondents as "somewhat important" for the selection of a place of business. On the other hand, this factor plays a less significant role in the area of transportation. If we evaluate this factor from the standpoint of sectors, then it is possible to state that the availability of information and communications technologies has a greater significance for the tertiary sector. The dependence of the evaluation of this factor was not demonstrated for the size of the enterprise, but on economic activities, despite close dependency, is very weak (determination index 0.06).

The presence of foreign companies can be considered as a soft localization factor and some authors have included it in business factors. In our research, this factor was included in regional and local, because we believe that foreign companies to a significant degree create and change the environment in a region and thereby affect the situation in the given locality. Therefore we include geographic proximity of foreign companies among business factors. The presence of foreign companies in and of itself includes a great number of positive aspects on the vicinity, as they are creators of new jobs and bring new technology and innovation to the region. The majority of domestic companies, however, perceive these benefits rather negatively and see in them only the possible threat to competition, therefore it is expected that this factor would not be too important for most companies (see fig. 1). This assumption was also confirmed, as $43 \%$ of respondents marked it as unimportant, $27 \%$ assessed it as neither positive nor negative in decision-making and only the remaining 30\% noted it as important when deciding on localization. It is possible to assume that this $30 \%$ of subjects either cooperate directly with foreign companies or are aware of their potential threat. It is also possible to state that high significance has not ascribed to this factor by any of the investigated economic branches. Relatively higher significance was recorded in the areas of accommodation, dining and also in retail and wholesale. At the same time, no significant difference was found in the evaluation among subjects of the secondary and tertiary sectors. The dependence of the evaluation of the factor on the size of the enterprise or on the economic branch did not demonstrate a level of significance of 5\%. 
The image of the region has been neglected in most cases as a localization factor, particularly in the past, when emphasis was placed particularly on reducing costs, and its growing significance was first recorded in recent years. The image of the region falls into soft localization factors, because it is not possible to immediately record it in company accounting. From the results of our research, it follows that the image of the region plays a significant role for almost half of companies, an unimportant role for a third and the remaining part noted that this factor does not affect them (see

fig. 1). The greatest significance for this factor was recorded in the areas of accommodation, dining, and hospitality and also in wholesale and retail, which apparently depends on the fact that a good image of the region attracts new potential consumers or also foreign tourists. On the other hand, the least significance was mentioned in the areas of professional, scientific and technical activities and at subjects in education. In case of the evaluation of sector differences, it is possible to state its greater significance in subjects in the area of services. On the other hand, the image of the region localization factor is not too significant for companies engaging in industrial production. It was possible to demonstrate the dependence of the evaluation of the factor on economic activities at the level of significance of $5 \%$ (close dependence of the measured determination index is overall just 0.08) and therefore the image of the region can be considered as a universal localization factor. The dependence of the evaluated factor on the size of the enterprise did not demonstrate a level of significance of $5 \%$.

Possibilities for use of free time ranks among soft individual localization factors, which has played a more significant role recently when deciding on localization, which depends primarily on the need for obtaining a qualified labor force. For qualified workers, free time activities have become continuously more significant when seeking available employment. In some cases, these even surpass pay valuation. Therefore, during the formulation of the research, it was anticipated that this factor would play an essential role during decision-making about placement. Overall, the research results did not confirm this assumption as the majority of those contacted (44\%) marked it as unimportant, $23 \%$ evaluate this factor as neutral and only the remaining $33 \%$ consider it as important (see fig. 1). The greatest attention is devoted to this factor in the areas of accommodation, dining as well as in construction and in activities related to real estate. The smallest average value and only 2.18 was measured in administrative and support activities. Differences between the investigated economic branches are certainly inconspicuous and therefore it is not possible to come to the definitive conclusion as to whether or not this factor has a greater decision-making significance for industrial companies or for subjects providing services. Weak dependence (closeness of 0.05) of the evaluation of this factor was again demonstrated only in economic activities, and therefore it is possible to consider the possibilities for using free time as a universal factor. The dependence of the evaluation of the factor on the size of the enterprise did not demonstrate a level of significance of $5 \%$.

\section{Investigated business factors}

The second investigated group included business localization factors, which, according to Viturka, may be considered as the most important localization factors. (Viturka, M. et al, 1998, s. 15) In the context of our research, the first investigated was geographic proximity to customers, which is generally considered as one of the most important hard localization factors, which the research results also confirmed. Specifically, $63 \%$ of the respondents evaluated this factor as important, $18 \%$ noted it had 
neither a positive nor negative impact and only one fifth marked it as unimportant. From the standpoint of comparing the importance among subjects of the secondary and tertiary sectors, no significance differences were recorded in the evaluation. The dependence of the evaluation of the factor on the size of the enterprise or on the economic branch did not demonstrate a level of significance of 5\%.

Furthermore, respondents evaluated geographic proximity to the competition, which is also considered as a traditional localization factor. In the case of this factor, a smaller impact was assumed on the decision-making of subjects, which the research results also confirmed. In principle, this conclusion applies for all branches. Average values fluctuate from 2.34 at professional, scientific and technical activities to 3.51 at administrative and support activities. A more significant role in the evaluation was not demonstrated even when comparing subjects aggregated into the basic sectors. But, the hypothesis of dependence of the evaluation of the factor on the type of economic activities at a 5\% level of significance was confirmed and this factor may be considered as universal. The dependence of the evaluation on the size of the enterprise, on the other hand could not be successfully demonstrated.

As the third of the business factors to be investigated was geographic proximity to suppliers, which is also included in the group of hard localization factors. The research results show that this factor is not too important when deciding on localization. Only roughly one third of subjects evaluated it as important, one third as unimportant and the remaining respondents considered it as indifferent during decision-making. From the research results, however, it follows that greater significance is assessed for it by industrial companies, which may be explained by more intensive sub-contractor relations and closer bonds between suppliers and customers. The dependence of the evaluation of the factor on the size of the enterprise was successfully demonstrated, the same as the dependence on the type of economic activity. In both cases, however, the closeness of dependence was weak (determination index 0.06).

The availability of supplemental services as another investigated business factor may also be included among hard localization factors. Supplemental services, however, markedly differ in individual branches of economic activities; therefore the same significance is not assumed in all investigated branches. The greatest average significance was assessed for this factor in the area of construction and in administrative and support activities, where it is possible to assume a greater significance of supplemental services than in other branches. On the other hand, supplemental services are less significant for the area of education. Greater significance of this factor was recorded in industrial enterprises where $49 \%$ of respondents noted it as important. In the area of services, $42 \%$ of respondents saw this as important. The dependence of the evaluation of the factor was demonstrated only on economic activity, not on the size of the enterprise. On the basis of the research results, it is possible to include this factor as universal.

Another investigated business localization factor was the option for cooperation with the competition, which can be characterized as on the borderline between hard and soft localization factors, while this does not concern a classic and long-term perceived localization factor. On the other hand, as a result of globalizing companies, its significance has already been increasing for a longer period. The research results, however, did not demonstrate a greater significance for this factor, as $42 \%$ of respondents marked it as unimportant, for $34 \%$ neither positive nor negative and only $24 \%$ of 
respondents assessed certain significance for it during selection of a place for localization. The smallest concern from cooperation with the competition and the greatest significance of this factor was recorded in the areas engaging in the supply of water. On the other hand, the least significance was recorded in professional, scientific and technical activities, in the sections of finance and insurance and in information and communications activities, where it is possible to assume a greater competitive struggle. From the standpoint of dependence, we can state that the evaluation of this factor is weakly dependent on the size of the enterprise (determination index 0.02) and also on economic activities (determination index 0.05) and it is possible to consider it as universal .

The proximity of other plants of the same enterprise was the final investigated business factor, which belongs in the group of traditional hard localization factors. In the case of our research, its greater significance was not anticipated primarily thanks to contacting a greater number of businesses with only one plant, which was also confirmed by the research results. Only one quarter of respondents declared certain significance when evaluating this factor. Greater significance was recorded in industrial companies, which often have more than one plan unlike from services where this factor was evaluated essentially by only $22 \%$ of respondents. Furthermore, the level of significance of $5 \%$ was confirmed that for larger enterprises this factor plays a more important role. On the other hand, the hypothesis about the dependence of the evaluation on economic activities at $5 \%$ of the level of significance was not possible to verify and the factor may not be considered as universal.

\section{Investigated employment factors}

Employment factors are generally one of the most essential groups of localization factors and it is possible to include in these groups nearly everything that touches on human capital. In the described research, attention was focused initially on employee mentality, which is the only employment localization factor to fall into the group of soft factors; its evaluation to a considerable degree is subjective and difficult to measure. It is possible to infer that employee mentality will play a more significant role in subjects with a need for more qualified human resources where employees are an essential element of the company. It is therefore possible to anticipate that employee mentality will be considered as a less significant factor by the industrial branch. From the research results, it follows that this factor may be considered generally as very significant when deciding on placement of the company, as nearly $65 \%$ of respondents marked it as important. Most frequently appeared the response that the factor is "absolutely important." The average evaluation reached the mark of 4 . The greatest emphasis was then measured in the section for accommodation and dining, as well as in information and communications activities and in construction. On the other hand, this factor surprisingly had less impact on the section of education and professional, scientific and technical activities, where it is most probable to assume that professionals from these sections would be willing to move due to employment. Nearly the same evaluation was found in industrial enterprises and service companies. Furthermore, the level of significance of 5\% was demonstrated for the hypothesis regarding the dependence of the evaluation of the factor on the size of the enterprise. This applies that with the increasing size of an enterprise, the significance of the employee mentality factor also increases. The hypothesis regarding the dependence of the evaluation on the enterprise and on the type of economic branch on the level of significance of $5 \%$ was not successfully demonstrated. 
Also evaluated was the availability of qualified human resources, which falls into the group of hard and also classic localization factors. From the research results, it follows that qualified human resources play a significant role when deciding on placement. This factor was marked as unimportant by only $17 \%$ of respondents, $13 \%$ of respondents marked it as a factor without positive or negative impact and for the remaining $70 \%$ of subjects this factor played an essential role. To acquire and maintain qualified human resources should be one of the primary goals in the context of regional strategy. The greatest significance of the factor was determined in the section of information and communications activities, in construction, accommodation and dining and in the section of wholesale and retail. On the other hand, this factor was evaluated as less important by respondents from the area education and in professional, scientific and technical activities. From the standpoint of sectors, greater importance was found at subjects of the secondary sector (75\% of respondents of industrial enterprises considered qualified resources as important for localization) in comparison with subjects in the tertiary sector (only $69 \%$ of subjects noted it as important). The dependence of the evaluation on the size of the enterprise or on economic activities, however, was not demonstrated at a level of significance of $5 \%$.

Investigated as the final work factor was labor price, which also belongs in the group of hard localization factors and the greater significance of this factor may be assumed. This was also confirmed by the research. The majority of subjects marked the factor as important when deciding on placement of the company. Specifically, $66 \%$ of respondents noted that labor price is important for them. The greatest significance of this factor from the standpoint of average evaluation was recorded in the sections of administrative and support activities and in accommodation and dining. Generally, greater importance was determined for this factor in the areas of services, where the factor was marked as important by $72 \%$ of respondents. The dependence of the evaluation of the factor on the size of the enterprise could not be demonstrated. But, the hypothesis on the dependence of the factor on economic activities was successfully demonstrated. The factor may be considered as universal for all branches.

\section{Investigated infrastructure factors}

Among infrastructure factors, it is possible to include, for example, the quality of highways, railways and waterways and the factor of proximity to larger airports. Evaluated in the research was initially the status of the transportation infrastructure, which is understood as facilities in the given area of infrastructure, i.e. such as the transportation hubs here, the state of the highways, as the distance in the given location from the highway or served by public transportation. From the research results, it follows that the state of the transportation infrastructure was evaluated by more than half of respondents as important when deciding on localization. The greatest significance was assessed for this factor in the section of water supply, in activities in the field of real estate and also in construction, wholesale and retail. The least significance was assessed for the state of transportation infrastructure by subjects in education, at professional, scientific and technical activities and in the section of finance and insurance. In the case of the sections engaging in services, generally it is possible to state a lower significance of the factor. This is also confirmed by the fact that greater significance was recorded in the secondary sector, where $73 \%$ of respondents noted that the factor is important for their placement, unlike from the tertiary sector where greater significance was assessed for it 
by only $63 \%$ of respondents. Dependence of the evaluation of the factor could not be demonstrated on the size of the enterprise or economic activities.

The final investigated localization factor was transportation costs, which belong among the oldest localization factors and form the basis for traditional localization theories. Transportation costs have undergone an interesting historical development, when initially they were considered as the main localization factor and with the development of transportation and technologies and as a result of relative shortening of the distances, their significance has gradually declined. Although the significance of transportation costs has relativized over time, from the research results, it follows that transportation costs continue to play a fundamental role when deciding on localization. A total of $55 \%$ of respondents marked it as important, for $23 \%$ it did not have either a positive or negative impact, and roughly the same percentage marked it as unimportant. The declining significance of this factor was recorded primarily in the areas of services, where the lesser significance of this factor was recorded in the area of education, as well as in professional, scientific, technical, administrative and support activities and in the sections of finance and insurance. On the other hand, transportation costs have the greatest impact for localization of industrial subjects, i.e. the sections of construction, processing industry and water supply. The dependence of the evaluation of the factor on the size of the enterprise did not demonstrate a level of significance of $5 \%$. But a weak dependence on the economic branch was successfully demonstrated (determination index 0.08) and therefore this factor may be considered as universal.

Several external influences affect the evaluation of localization factors and the goal of research engaging in this issue is primarily to characterize the amount of these impacts as much as possible. From the results of our research, it is possible to come to the general conclusion that the investigated localization factors influence the decision-making of businesses particularly in the branches of construction, accommodation and dining as well as wholesale and retail. Therefore, it is desirable to concentrate precisely on these investigated localization factors in regional strategy. If a regional strategy hopes to attract this economy to its locality, it should focus more on our investigated factors. On the other hand, the investigated factors manifest themselves the least for professional, scientific and technical activities, in education and in the section of "other activities." If we evaluated localization factors according to the mode, then individual factors would be most often evaluated as "somewhat important" and "absolutely important" for subjects of the processing industry, as well as in construction, accommodation and in information and communications activities. On the other hand, most frequently, the investigated factors were evaluated as an unimportant localization factor for subjects in the branches of transportation, education, water supply and activities related to waste. In these sections, the investigated factors do not play a more significant role when deciding on localization and they are spatially neutral.

Localization theory as such is considered a relatively young science and also in the context of research, localization factors have not been given sufficient attention. By certain limitation to the presented research, data are processed for all economic branches according to the CZ-NACE classification, while the given areas these are very extensive in some cases. For a more exhaustive research of branches, it would therefore be necessary to conduct repeated analyses, over a longer time period and to expand the sample of respondents. It would then be possible to analyze how the evaluation of factors develops over time, where it is possible to observe the greatest differences and by which these differences are given. 
The investigated localization factors may be categorized according to the dependence of the evaluation of the enterprise on the size of the economic subject and economic activities as follows:

- In the first category are factors for which the hypothesis regarding the dependence of the evaluation of the factor on the size of the enterprise or even on the economic activities could not be successfully demonstrated. Into this area belong facilities of the city, presence of foreign companies, geographic proximity to customers, the status of the transportation infrastructure and the availability of qualified human resources.

- Into the second category may be included factors for which the hypothesis regarding dependence of the evaluation both on the size of the enterprise as well as on the type of economic activities was confirmed. Both hypotheses were confirmed by the research for the options for cooperation with the competition, geographic proximity to suppliers and at ecological requirements, conditions and standards. In the case of these factors, it is possible to reach the conclusion that the evaluation of the factor is dependent on the economic activity of the subject and the factor may be considered as universal. Furthermore, it applies at these three factors that their significance increases with the size of the company.

- In the third category belong factors that may be considered as universal, but for which the hypothesis regarding the dependence of the evaluation of the factor on the size of the company was not confirmed. Among these factors are the quality and attractiveness of the territory, the tradition and history of the locality, the economic status of the region, the availability of non-residential and office spaces, the prices for land and buildings, the amount of taxes and fees, the availability of information and communications technologies, the image of the region, the possibility for using free time, the geographic proximity to the competition, the availability of supplemental services, the price of labor and transportation costs.

- We include in the fourth category those factors for which a dependence was demonstrated of the evaluation only on the size of the company in the sense of the larger the company, the more important the evaluation. This hypothesis was demonstrated for the factors proximity to other plants of the same company, employee mentality, quality of the employment office, cooperation with state authorities and the availability and quality of research facilities.

For comparison, it is possible to present the results of similar research by Damborský and Wokoun, who conducted the following categorization of factors linked to local or regional supplier or customer markets according to the significance on the localization process:

- The first category consists of factors whose significance is indispensible for small and medium-sized companies across the sector and size structure. However, only geographic proximity to the sales market falls into this category.

- Into the second category belong factors that are not significant even in one size and sector category. Here belong the option to obtain an exclusive market position, the possibility to cooperate with the competition, and the acquisition of information from the competition.

- The third category consists of factors that are significant only in some of the monitored sizes or sector categories. Among these factors are geographic proximity 
to the competition, geographic proximity to suppliers, availability of complementary services, economic growth of the region and copying competition.

From a comparison of both researches, it follows that a large number of companies continue to be affected by classic hard localization factors, primarily the geographic proximity to the sales market. Localization decision-making is a very complex process, which fundamentally affects the subsequent development, profitability and prosperity of the given economic subject. Since the reasons and factors for localization decision-making of companies are often very subjective matters, it is complicated to measure them in any way. For this reason, a valuation scale was selected, whereby it is possible to compare parts of factors, to what degree they are significant for individual economic activities. Economic subjects and the reasons for their localization have a fundamental impact on the situation in the region and in the given locality; therefore localization factors should be given sufficient attention in regional development strategy. In the context of the research project, reasons upon which localization decisions depend were clarified as well as which have a significant impact on them. On the basis of the research results, it is possible to state that most companies evaluate the locality of a future business from the standpoint of several factors.

This article was compiled in the context of the project "Analysis of selected localization factors and their comparison according to individual economic activities" implemented with the financial support for specific university research at the School of Economics at the Technical University in Liberec in 2011.

\section{References}

Blažek, J., Uhlí̌, D. (2002). Teorie regionálního rozvoje: nástin, kritika, klasifikace. [Theory of regional development: summary, critique, classification]. $1^{\text {st }}$ edition. Praha: Karolinum. 210p.

Grabow, B., Hollbach-Gromig, B. (1995). Weiche Standortfaktoren. Schriften des Deutschen Institut für Urbanistik Band, 89. Stuttgart-Berlin-Köln: Dt. Gemeindeverlag.

He, C., et al (1997). Locational distribution and spatial diffusion of foreign direct investiments from Hongkong and Macao in mainland of China [online]. Chinese Geogrephical science, vol. 7 , iss. 4 ,

s. 328 - 338 [ibidem 2011-09-28]. Retrievable from: http://search.proquest.com/docview/204246003/13258520C1F46BDF746/1?accountid=17116.

Hlaváček, P. (2009).The foreign direct investments in the Ústí region: Theory, actors and space differentiation. E+M Ekonomie a Management. vol. 12, iss. 4, s. 13-27. ISSN 1212-3609.

Hnilicová, H., Bártlová S. (2000). Vybrané techniky a metody zjištování spokojenosti pacientů. [Selected techniques and methods for determining patient satisfaction]. st $^{\text {st }}$ edition. Brno: Institut pro další vzdělávání pracovníků ve zdravotnictví. 118p.

Ježek, J. (1998). Prostorová a regionální ekonomika. [Spatial and regional policy].1 ${ }^{\text {st }}$ edition. Plzeň: Vydavatelství Západočeské univerzity. 238p.

Kožíšek, J., et al (2008). Statistická a rozhodovací analýza, [Statistical and decision-making analysis]. $1^{\text {st }}$ edition. Praha: ČVUT. 252p.

Krugman, P., Obstfeld, M. (2009). International Economics: Theory \& Policy. $8^{\text {th }}$ edition. Pearson:Addison Wesley. 706p.

Lechenko, R. (2003). Does place still matter? Accounting for Income Variation Across American Indian Tribal Areas. [online]. Economic Geography, vol. 79, iss. 4, s. 365 - 386 [ibidem 
2011-09-28]. Retrievable from: http://search.proquest.com/docview/235594797/132585 6D250686DC073/1?accountid=17116

Matoušková, Z., et al (2000). Regionální a municipální ekonomika. [Regional and municipal economies] Praha: VŠE. $1^{\text {st }}$ edition. 156p.

Ponikelský, P., et al (2008). Ekonomika municipalit a regionů [The economy of municipalities and regions] [online]. Praha: VŠRR [ibidem. 2011-08-19]. Retrievable from: http://www.vsrr.cz/reg/kestazeni/emr2.pdf.

Rumpel, P., et al (2008). Měkké faktory regionálního rozvoje. [Soft factors of regional development] $1^{\text {st }}$ edition. Ostrava: Repronis. 186p.

Sass, M. (2010). Foreign direct investments and relocations in business services - what are the locational factors? The case of Hungary. [online]. Cuadernos de Relaciones Laborales, vol. 28, iss. 1, s. 45 - 63 [ibidem 2011-07-15]. Retrievable from: http://search.proquest.com/ docview/734616383/132584BA2AE2E8C407C/1?accountid=17116.

Simango,CH. (1993). Strategic locational factors influencing foreign investment. [online]. European Business Review, vol. 98, iss. 4, s. 7 [ibidem 2011-09-28]. Retrievable from: http://search.proquest.com/docview/225428717/132584DF30818061CEC/1?accountid $=17116$

Slach, O., et al (2007). J. Měnící se význam turdých a měkkých faktorů rozvoje. [The changing significance of hard and soft factors of development] In: SBORNÍK PÉISPĚVKU Z X. MEZINÁRODNÍHO KOLOKVIA O REGIONÁLNÍCH VĚDÁCH. $1^{\text {st }}$ edition. Brno: Masarykova univerzita. $409 \mathrm{p}$.

Stability, skilled labour and infrastructure top locational factors for foreign affiliates. [online]. Yemen Times, iss. 1113, 2007 [ibidem 2011-09-28]. Retrievable from: http://search.proquest.com/docview/429792134/13258504D28573CCE3E/1?accountid=17116

Traxler, J. (2009). Indie [online]. Finmag, 2009 [ibidem 2011-09-28]. Retrievable from: http://www.finmag.cz/cs/finmag/ekonomika/indie/.

Viturka, M. et al (1998). Investiční atraktivita vybraných měst České republiky. [Investment attractiveness of selected cities]. $1^{\text {st }}$ edition. Brno: Vydavatelství MU. 120p.

Wasylenko, M. (1991). Empirical Evidence on Interregional Business Location Decisions and the Role of Fiscal Incentives in Economic Development. In: HERZOG, H. W., SCHLOTTMANN, A. M. eds., Papers of a conference Industry location and public policy. $1^{\text {st }}$ edition. University of Tennessee, s. 13 - 30.

\section{Ing. Eliška Jirásková}

Technical University of Liberec, Faculty of Economics

Department of Business Economics

Voroněžská 13, 46117 Liberec

+420485352245

eliska.jiraskova@tul.cz

\section{doc. Ing. Miroslav Žižka, Ph.D}

Technical University of Liberec, Faculty of Economics

Department of Business Economics

Voroněžská 13, 46117 Liberec

+420485352345

miroslav.zizka@tul.cz 